\title{
Development of Technologies And Analytical Capabilities For Vision 21 Energy Plants
}

\author{
QUARTERLY PROGRESS REPORT
}

Reporting Period Start Date: July 1, 2003

Reporting Period End Date: September 30, 2003

Maxwell Osawe, Madhava Syamlal, Krishna Thotapalli, and Stephen Zitney

Fluent Inc.

Woodrow Fiveland and David Sloan

ALSTOM Power

Frank Joop and Philip Simon

Intergraph Corporation

K. Joseph Cleetus

Concurrent Engineering Research Center, West Virginia University

October 302003

DOE Cooperative Agreement No: DE-FC26-00NT40954

Fluent Inc.

10 Cavendish Court, Lebanon, NH 03766

ALSTOM Power

US Power Plant Laboratories, 2000 Day Hill Road, Windsor, CT 06095

Aspen Technology, Inc.

Ten Canal Park, Cambridge, Massachusetts 02141-2200

Intergraph Corporation

One Madison Industrial Estate, Huntsville, AL 35894

Concurrent Engineering Research Center, West Virginia University

886 Chestnut Ridge Rd., Morgantown, WV 26506 


\section{DISCLAIMER}

This report was prepared as an account of work sponsored by an agency of the United States Government. Neither the United States Government nor any agency thereof, nor any of their employees, makes any warranty, express or implied, or assumes any legal liability or responsibility for the accuracy, completeness, or usefulness of any information, apparatus, product, or process disclosed, or represents that its use would not infringe privately owned rights. Reference herein to any specific commercial product, process, or service by trade name, trademark, manufacturer, or otherwise does not necessarily constitute or imply its endorsement, recommendation, or favoring by the United States Government or any agency thereof. The views and opinions of authors expressed herein do not necessarily state or reflect those of the United States Government or any agency thereof. 


\begin{abstract}
This is the twelfth Quarterly Technical Report for DOE Cooperative Agreement No: DE-FC2600NT40954. The goal of the project is to develop and demonstrate a software framework to enable virtual simulation of Vision 21 plants.

During the last quarter the software development was completed and the testing of the integrated software was completed. A user manual was written to complete software documentation. An installation CD-ROM including the following items was written: software installer, controller source code, proprietary CORBA wrapper templates for building local and remote servers, publicly available source code of the ACE/TAO CORBA library that needs to be built before compiling the controller source code, pre-built binaries of the publicly available XERCES XML library, and a PDF version of the software user's manual. The software was delivered to DOE.

During the last quarter software demonstration tasks were completed. A few additional load points of Demo Case 1 were solved. Integrated simulations of Demo Case 2 with the proprietary HRSGSIM code and FLUENT CFD model were completed. The final task report describing Demo Case 1 and Demo Case 2 simulation results was written and delivered to DOE.
\end{abstract}




\section{TABLE OF CONTENTS}

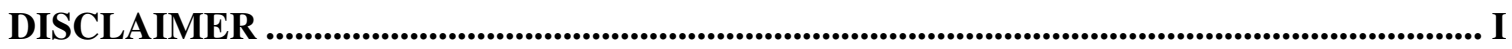

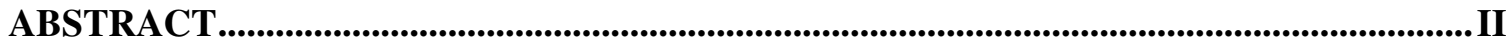

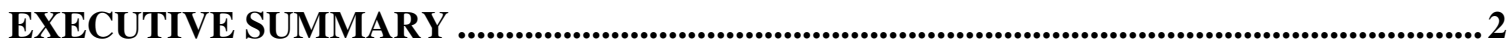

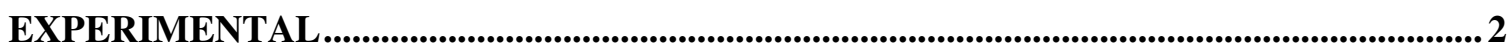

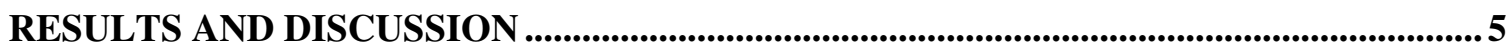

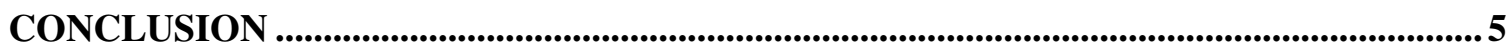

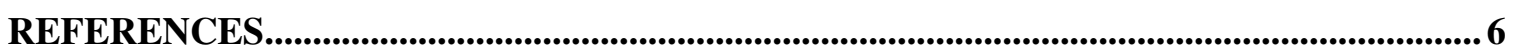

LIST OF ACRONYMS AND ABBREVIATIONS ................................................................. 7 


\section{EXECUTIVE SUMMARY}

Testing of the integrated software was completed (Task 2.21). A user manual was written to complete software documentation (Task 2.22). An installation CD-ROM including the following items was written: software installer, controller source code, proprietary CORBA wrapper templates for building local and remote servers, publicly available source code of the ACE/TAO CORBA library that needs to be built before compiling the controller source code, pre-built binaries of the publicly available XERCES XML library, and a PDF version of the software user's manual. The software was delivered to DOE (Task 2.24). A few additional load points of Demo Case 1 were solved (Task 4.1). Integrated simulations of Demo Case 2 with the proprietary HRSGSIM code and FLUENT CFD model were completed (Task 4.2). The final task report describing Demo Case1 and Demo Case 2 simulation results was written and delivered to DOE (Task 4.3). The work on writing the project final report was continued (Task 7.0).

\section{EXPERIMENTAL}

\section{Task 2.0 Software Integration}

\section{$\underline{\text { Task 2.21 Test Integrated Software }}$}

- Tested Controller v0.9.6 (based on CAPE-OPEN v1.0) with Aspen Plus 12.1 kit 115 and FLUENT 6.1.18 and provided feedback to the software development team.

- Tested the use of CAPE-OPEN CFD parameters in Aspen Plus analysis tools (i.e., optimization, case studies, sensitivity analysis). Used Aspen Plus to optimize overall process yield by manipulating impeller speed of FLUENT CSTR.

- Tested procedure for using the FLUENT Configuration Wizard (parameter rpvar option) to make FLUENT calculated variables (e.g., fuel cell voltage) available as parameters for use in Aspen Plus analysis tools.

- Carried out extensive integration testing using selected problems to assess the performance, reliability and robustness of the Controller.

- Tested several new versions of the Controller (v0.9.6b, v0.9.6c, and v0.9.7) with Aspen Plus 12.1 Release Candidate 8 and FLUENT 6.1.18.

- Tested the general Configuration Wizard and provided feedback to the software development team.

$\underline{\text { Task } 2.22 \text { - Documentation }}$

A user manual was written. A PDF version of the manual is included in the installation CD-ROM.

Task 2.23-Software Support

MOO collaborated with DGS to track down a perennial Aspen Plus CO error message that get thrown at some random load points during integrated simulations. MOO recommended an OS upgrade from Window NT to Windows 2000. The latter is the officially supported Windows platform and the recommendation appears to have cured the reported problems.

\section{$\underline{\text { Task 2.24 Prepare release version }}$}

Implemented the functionality to update parameter values in the Edit Model GUI at run-time so that the user can be sure of what parameters were actually employed by the process simulator in the most recent COSE iteration. This feature is particularly useful in checking the value of 
parameter(s) in the Edit Model GUI during coupled sensitivity analysis with an external unit operation model such as Fluent.

Completed the development of the Controller XML writer, which provides a parallel functionality to the Fluent configuration wizard for writing out both the Master and Solver XML files required by the Controller Edit Model GUI. This functionality would be particularly useful for presenting proprietary model parameters and other pertinent model information to the Controller subsystem.

Completed the implementation of the Controller persistence functionality. The new feature would be tested with Aspen Plus 12.1 Release Candidate 7, which will hopefully contain bug fixes required for restoration of the persisted flow sheet file without crashes. With this new feature, a flow sheet file containing a CAPE-OPEN can now be saved and be fully restored in a new session, along with the automatic activation of the associated external solver process or processes without user intervention.

A few bugs that surfaced in the first release candidate build of the software were tracked down. One of the identified bugs, which has now been fixed, was such that a new page of the Edit Model tab dialog gets displayed on attempting to dismiss the GUI. As a result, the Controller is unable to activate the selected external unit operation process.

Prepared a release build of the proprietary Regression model.

Prepared the installation CD-ROM, which includes the following:

- Software installer

- Controller source code

- Proprietary CORBA wrapper templates for building local and remote servers

- Publicly available source code of the ACE/TAO CORBA library which needs to be built before compiling the Controller source code

- Pre-built binaries of the publicly available XERCES XML library

- A PDF version of the software user's manual.

Detailed instructions for using the supplied CORBA templates are contained in the user's manual. A copy of the Qt GUI library must be obtained from Trolltech (www.trolltech.com) to build the Controller source code.

The release version of the software was delivered to the DOE.

\section{Task 4.0 Run Integrated Simulations}

Task 4.1 Simulations of Case 1. After installing the new Windows 2000 operating system and the (almost complete) eradication of the ECape errors, it was possible solve Case 1 at the load points 19,17 , and $15 \mathrm{MW}$.

Task 4.2 Simulations of Case 2. (1) The proprietary HRSGSIM code was successfully run in conjunction with Aspen Plus. (2) The scheme file was set up to allow for transfer of information between Fluent and the steam cycle for Demo Case 2. The Fluent case was modified so that its species list corresponded to the species list in the Aspen Plus flow sheet. Attempts were made to run the case. (3) The presence of an unresolved error (ECapeError), which seriously interferes with the computations, is presumed to be due to the Windows NT operating system (OS) on the PC. The NT OS was replaced with Windows 2000, and all of the pertinent software was reinstalled on the hard drive. The new OS permitted Case 2 to run without persistent ECape errors. 
(4) A 3-minute time-out error was encountered, which precludes the reading in of larger steam tables. Only the 100x100 tables can be read in within the prescribed limit. (5) The CFD block has been manually sequenced (as many as 16 times in a series) in order to try to propagate the information throughout the cycle and get the superheat outlet temperature from the CFD case to stabilize. Ideally, more loops would be necessary in the sequence in order for the superheat outlet temperature to truly level out, but the 16 loops was sufficient for the code to successfully find a solution at the 6 discrete load points from 100\% to 50\% load. (Randy Field, Aspen Tech, proposed an alternate methodology that gives greater control to Aspen Plus.)

Task 4.3 Task Report of Case 1 and 2 Results. The final task report of the Case 1 and Case 2 simulation results has been completed. The report was delivered to DOE.

\section{Task 5.0 Advisory Board Activities}

No activity this quarter.

\section{Task 7.0 Project Management}

Final report:

Updated the section on Integrated Model Development and Use in the Vision 21 final report.

\section{Issues and Resolution:}

Task 5.0 Advisory Board: A final Advisory Board meeting is outstanding. In lieu of the regular advisory board meeting, the members of the board have been invited to attend a Web Seminar scheduled for October $30^{\text {th }}$, which will give the Advisory Board members a demonstration of the software. The Advisory Board members have been requested to e-mail their feedback to the project team. During the project extension period we may consider conducting another advisory board meeting.

\section{Progress forecast for the next quarter:}

- Task 7.0 Project management

- Complete the final report

- Plan the project extension

Project Milestones:

\begin{tabular}{|l|l|l|l|l|}
\hline Task & Milestone/Deliverables & \multicolumn{3}{|c|}{ Completion Date } \\
\cline { 3 - 5 } & & Original & Revised & Actual \\
\hline 1.0 & Project Management Plan & $1-30-01$ & & $1-23-01$ \\
\hline 2.2 & User Requirements Document (URD) & $3-15-01$ & & $3-28-01$ \\
\hline 2.3 & $\begin{array}{l}\text { Software Requirements Specifications } \\
\text { (SRS) }\end{array}$ & $4-15-01$ & & $5-13-01$ \\
\hline 2.6 & Software Design Documentation & $5-15-01$ & $7-15-01$ & $8-10-01$ \\
\hline 2.7 & Software Development Plan & $6-30-01$ & $1-21-02$ & $1-21-02$ \\
\hline 2.7 & Working Test Case 1 & $6-30-01$ & $10-30-01$ & $10-30-01$ \\
\hline 2.8 & Demonstrate CFD database & $9-30-02$ & & $9-30-02$ \\
\hline 2.10 & $\begin{array}{l}\text { Prototype with reaction kinetics data } \\
\text { transfer }\end{array}$ & $12-31-01$ & & $12-31-01$ \\
\hline 2.11 & COM-CORBA bridge - 1 & $6-30-02$ & & $6-30-02$ \\
\hline 2.12 & Transfer physical properties & $12-30-02$ & & $9-30-02$ \\
\hline
\end{tabular}




\begin{tabular}{|c|c|c|c|c|}
\hline & & \multicolumn{3}{|c|}{ Completion Date } \\
\hline 2.13 & GUI & $6-30-02$ & $7-31-02$ & $8-31-02$ \\
\hline 2.14 & CFD Viewer & $9-30-02$ & $12-30-02$ & $12-30-02$ \\
\hline 2.15 & Proprietary model template & $12-30-02$ & $5-15-03$ & $6-15-03$ \\
\hline 2.16 & Session Management & $12-30-02$ & $3-30-03$ & $3-30-03$ \\
\hline 2.17 & COM-CORBA bridge - 2 & $9-30-02$ & $5-15-03$ & $6-15-03$ \\
\hline 2.18 & Configuration Wizard & $6-30-02$ & $9-15-02$ & $9-15-02$ \\
\hline 2.19 & Low Order model & $9-30-02$ & & $9-30-02$ \\
\hline 2.20 & Aspen Plus analysis tools & $12-30-02$ & $5-30-03$ & $6-30-03$ \\
\hline 2.21 & Test integrated software & $12-30-02$ & $8-30-03$ & $9-15-03$ \\
\hline 2.22 & Documentation & $3-30-03$ & $8-30-03$ & $9-25-03$ \\
\hline 2.24 & Prepare release version & $6-30-03$ & $8-30-03$ & $9-25-03$ \\
\hline 3.1 & Demonstration Case 1 selection & $1-31-01$ & $5-15-01$ & $4-30-01$ \\
\hline 3.2 & Demonstration Case 2 selection & $9-30-01$ & $7-15-02$ & $8-31-02$ \\
\hline 4.1 & $\begin{array}{l}\text { Demonstration Case } 1 \text { simulation } \\
\text { completed }\end{array}$ & $6-30-02$ & $5-30-03$ & $6-30-03$ \\
\hline 4.2 & $\begin{array}{l}\text { Demonstration Case } 2 \text { simulation } \\
\text { completed }\end{array}$ & $5-30-03$ & $8-30-03$ & $9-30-03$ \\
\hline 4.3 & $\begin{array}{l}\text { Report on Demonstration Case } \\
\text { simulations }\end{array}$ & $7-30-03$ & $8-30-03$ & $10-15-03$ \\
\hline 5.1 & Advisory Board Meeting & $3-31-01$ & & $6-6-01$ \\
\hline 5.2 & Advisory Board Meeting & $9-30-01$ & $11-7-01$ & $11-7-01$ \\
\hline 5.3 & Advisory Board Meeting & $3-31-02$ & $6-12-02$ & $6-10-02$ \\
\hline 5.4 & Advisory Board Meeting & $9-30-02$ & $12-30-02$ & $12-18-02$ \\
\hline 5.5 & Advisory Board Meeting & $3-31-03$ & $5-6-03$ & $5-6-03$ \\
\hline 5.6 & Advisory Board Meeting & $7-30-03$ & & $10-30-03$ \\
\hline 7.0 & Quarterly reports to DOE & $\begin{array}{l}\text { Every } \\
\text { quarter }\end{array}$ & & $\begin{array}{l}\text { 1/30/01, } \\
4 / 20 / 01, \\
7 / 20 / 01, \\
10 / 20 / 01, \\
1 / 29 / 02, \\
4 / 30 / 02, \\
7 / 30 / 02, \\
11 / 01 / 02, \\
1 / 30 / 03, \\
4 / 30 / 03, \\
7 / 30 / 03 \\
10 / 30 / 03\end{array}$ \\
\hline 7.0 & Draft Final Technical Report & $10-30-03$ & & \\
\hline 7.0 & Final Technical Report & $12-30-03$ & & \\
\hline
\end{tabular}

\section{RESULTS AND DISCUSSION}

During the last quarter we completed the development of the framework for integrating equipment (CFD and proprietary) and plant models. This being a software development and demonstration project there are no experimental or simulation results to report and discuss.

\section{CONCLUSION}

During the last quarter we completed the development of a framework for integrating equipment and plant models. The software and documentation were delivered to DOE. 


\section{REFERENCES}

1. Syamlal, M. and W.A. Fiveland, "Roadmap for the Development of a Vision 21 Simulator," presented at The 29th International Technical Conference on Coal Utilization \& Fuel Systems, Clearwater, Florida, March 10-14, 2003.

2. Syamlal, M. J.I. Madsen, W.A. Rogers, and S.E. Zitney, "Application of an Integrated Process Simulation and CFD Environment to Model Fuel Cell Systems," Presented at the AIChE Spring National Meeting, March 30 - April 3, New Orleans, LA (2003). 


\section{LIST OF ACRONYMS AND ABBREVIATIONS}

Personnel Name
Woodrow Fiveland
John L. Marion
David G. Sloan
Herb Britt
Randy Field
Steve Zitney
Joe Cleetus
Igor Lapshin
Lewis Collins
Paul Felix
Ahmad Haidari
Barb Hutchings
Maxwell Osawe
Krishna Thotapalli
Madhava Syamlal
Frank Joop
Philip Simon

Name

ActiveX

AHGO

AHAO

API

$\mathrm{C}++$

CERC

CFD

CAPE-OPEN

CASE

$\mathrm{CO}$

CO wrapper

$\mathrm{COM}$

CORBA $\underline{\text { Affiliation }}$

ALSTOM Power
ALSTOM Power
ALSTOM Power
AspenTech
AspenTech
AspenTech
CERC
CERC
Fluent
Fluent
Fluent
Fluent
Fluent
Fluent
Fluent
Intergraph
Intergraph

ALSTOM Power

ALSTOM Power

AspenTech

AspenTech

AspenTech

CERC

Fluent

Fluent

Fluent

Fluent

Fluent

Intergraph

$\underline{\text { Description }}$

A Microsoft technology built on top of COM that extends the basic capabilities of OLE to allow components to be embedded in Web sites. Air Heater Gas Outlet (e.g., referring to the flue gas exit temperature from the air preheater)

Air Heater Air Outlet (e.g., referring to the air gas exit temperature from the air preheater; after the air preheater, the heated air goes into the boiler)

Application Programming Interface.

$\mathrm{C}++$ programming language.

Concurrent Engineering Research Center, WVU.

Computational Fluid Dynamics.

Computer Aided Process Engineering - Open Simulation Environment Interface definitions for exchanging information with process simulation software (www.colan.org).

Computer Aided Software Engineering.

CAPE-OPEN

The code for implementing CO interfaces in a software.

Component Object Model - Refers to both a specification and

implementation developed by Microsoft Corporation that provides a framework for integrating software components.

The Common Object Request Broker Architecture is a specification of a standard architecture for object request brokers (ORBs). A standard architecture allows vendors to develop ORB products that support application portability and interoperability across different programming languages, hardware platforms, operating systems, and ORB

implementations (www.omg.org). 
COM-CORBA Bridge Software for translating COM objects to CORBA objects and vice versa. This component of the Vision 21 Controller will permit Aspen Plus running under Windows to exchange data with Fluent running under UNIX.

\section{CORTEX \\ COSE \\ CSTR \\ DCOM}

DLL

DO

Doxygen

DOE

EO

GCO

GOF

GUI

HEX

HRSG

HRSGSYM

HX

IDL

INDVU

Java

LTSH

Middleware

NETL

OLE

PFD

Python

QT

RP\&L

RUP

Scheme

SDD

SM

SRD

SDP

SGI
FLUENT's user interface engine.

CAPE-OPEN Simulation Executive (e.g., Aspen Plus).

Continuous Stirred Tank Reactor.

Distributed Component Object Model - An extension of COM that

allows software components to be distributed over a network.

Dynamic link library. A collection of small programs, any of which can be called when needed by a larger program that is running in the computer.

Discrete Ordinates (radiation model).

A documentation system for C++, Java, IDL (Corba/COM) and C.

U.S. Department of Energy.

Equation oriented solution strategy for solving flowsheet models.

Global CAPE-OPEN, an extension of the CAPE-OPEN project.

(www.global-cape-open.org)

Gang of Four - the four authors of a book, which originally categorized

and described several software design patterns.

Graphical User Interface.

Fluent heat exchanger module.

Heat recovery steam generator.

ALSTOM Power in-house code for simulating HRSG.

Heat Exchanger

Interface definition language, which is used for defining the

communications between software components linked through a

middleware.

ALSTOM Power in-house code for the analysis and design of the gas

side of a powerplant.

Java programming language.

Low temperature super heater.

Connectivity software that consists of a set of enabling services that

allows multiple processes running on one or more machines to interact across a network.

National Energy Technology Laboratory.

Object Linking and Embedding. Builds on COM to provide services

such as object "linking" and "embedding" that are used in the creation of

compound documents (documents generated from multiple tool sources).

Process Flow Diagram.

Python programming language.

Software used for developing the V21 Controller GUI.

Richmond Power and Light power plant.

The Rational Unified Process ${ }^{\circledR}$ - a web-enabled set of

software engineering processes that provides guidance to streamline

development activities.

Programming language used in CORTEX (FLUENT)

Software Design Document.

Sequential modular solution strategy for solving flowsheet models.

Software Requirements Document.

Software development plan

Silicon Graphics Inc. 


Swing
UDF
UGM
UML
URD
Use Case
VB
Visual Basic
V21 Controller

WVU

XML
A Java GUI tool kit.

User defined function. A program written in $\mathrm{C}$ for enhancing the functionality of FLUENT.

Users Group Meeting.

Unified Modeling Language.

User Requirements Document.

The specification of a sequence of actions, including variants, that a system can perform, interacting with actors (users) of the system.

Visual Basic programming language.

Visual Basic programming language.

The software being developed in this project for linking CFD and other proprietary equipment-level models with process simulation models. West Virginia University.

Extensible Markup Language: A metalanguage -- a language for describing other languages -- which lets one create their own markup language for exchanging information in their domain (music, chemistry, electronics, hill-walking, finance, surfing, CFD, process simulation). 